\title{
Norwegian research and development in the field of ship automation
}

\author{
IBB HÖIVOLD \\ Keywords : Ship automation. computer applications, collision avoidance \\ This survey paper briefly describes how ship automation was developed in Norway as a \\ joint effort of research institutes, industrial companies and the shipping companies and \\ organizations. The survey does not cover all industrial activities but mainly those which \\ have been the result of grants from The Royal Norwegian Council for Scientific and Indus- \\ trial Research (NTNF). The survey covers these activities, beginning with the efforts to \\ obtain unmanned machinery space operation by means of conventional instrumentation \\ and ending up with sophisticated computer-based systems for navigation and engine room \\ applications.
}

\section{Introduction}

The fact that Norway has, to a great extent, been relying on shipping as an important activity means that it is of special interest to introduce automation as a means of staying competitive. In many fields, Norwegian shipping is known for its pioneering efforts and this is also the case regarding ship automation. We succeeded early in establishing cooperation between research institutes, shipping organizations and industry in order to explore how new technologies could be applied for the benefit of safer and more economic operation of the merchant marine. In addition, NTNF was willing to finance some key projects which have had a considerable impact on the development of Ship Automation.

The NTNF-financed activity was started in 1960 but before this, Norwegian industry developed special instruments for engine room applications. An example is that of the Autronica company in Trondheim, which had developed advanced equipment for temperature monitoring. However, the new trend beginning in the sixties was to design systems aiming at a different way of operating an engine room. This system design is the main subject of this survey.

\section{The first steps of paper work}

The start of Norwegian ship automation system design dates from October 1959. Some talks then took place with representatives from The Ship Research Institute of Norway (NSFI), visiting the University of California at Berkeley.

At that time, the American Maritime Administration had started a study on ship automation with the preliminary objective of reducing the crew by one third and with the ultimate objective of examining the possibilities of unmanned ship operation. Many of the US universities took part in this study over a period of some years, but it did not result in any development work or any installations on board ships.

Received 12 February 1983.

$\dagger$ Norsk Data A.S, P.O. Box 25, Bogerud, 0694 Oslo 6, Norway. 
This initiative inspired us to make a similar study, but with a more realistic objective. It was decided to examine the use of modern instruments in order to specify an installation which reduced manual work to an economic minimum. This theoretical study was started in the spring of 1960 at NSFI. It was supported by Servoteknisk Utvalg of NTNF and financed by NTNF.

\section{The first experimental installation}

After more than two years of theoretical studies, it was decided in the autumn of 1962 that the results looked promising but that it was necessary to get some practical experience, especially concerning reliability of instruments in the maritime environment. For this purpose, it was proposed to design an experimental installation which could be tested on board a suitable ship. It was furthermore decided that the objective of the installation should be to operate the engine room unattended at night. At this time this seemed to be a realistic possibility.

An invitation to participate in this project, partly financed by NTNF, was sent to the shipping companies in Norway, but at this time it did not meet with any positive response. At last, however, Norsk Hydro decided to take part in the project. The company was an ideal partner, having extensive experience in using automatic process control in chemical plants and operating a fleet of product carriers for the transport of ammonia.

This project was started in July 1963 with a project group consisting of participants from NSFI, the research organization The Foundation for Scientific and Industrial Research at the Norwegian Institute of Technology (SINTEF), the classification society Det norske Veritas (DnV) and Norsk Hydro. M/S 'Haugvik' of Norsk Hydro was appointed to receive the experimental installation whilst it was at the Akers shipyard for rebuilding of tanks.

In February 1964, M/S 'Haugvik' left the yard with most of the installation completed. As a result of an idea introduced by NSFI, it was decided that the engine room should be monitored from a panel installed on the bridge. The idea was that the bridge officers should be trained to operate this panel but, for several reasons, it was impossible to obtain permission for this change of organization. Although most of the instrumentation performed satisfactorily, it was not possible to operate the ship with an unattended engine room.

The project, however, resulted in two successful achievements. The first was that normal instruments, being used in chemical plants, performed satisfactorily onboard and it could be concluded that they were capable of meeting the needs of ship automation. Mainly pneumatic instruments were being used.

The second achievement was the development of a system for remote bridge control of the main engine, a system which is necessary for unattended engine room operation. This system was developed by the joint effort of SINTEF and DnV, and it was entirely based upon the use of pneumatic tachometer and an ordinary pneumatic PID-controller for speed control of the main engine. After a period with mechanical difficulties, this main engine remote control was successfully put into final operation, representing a more flexible solution than the engine telegraph.

Even if the 'Haugvik'-project did not result in a final solution for unattended engine room operation, it gave the participants useful experience for further work and represented an important move forward 


\section{Industrializing the first results}

In the following years ship automation was established as an industrial activity in some companies. An important contribution to this activity was that Det norske Veritas was the first classification society to introduce, in 1966, a special class for automated ships. It was named EO-class for periodically unattended engine room, and recommendations or requirements were published for this mode of operation. Some shipowners soon accepted this class for their new buildings.

In 1965 Norcontrol was formed as a company specializing in ship automation, being a joint effort of Norsk Hydro, Noratom and $\mathrm{A} / \mathrm{S}$ Kongsberg Våpenfabrikk. Norcontrol developed an electronic bridge control system, AutoChief, for their EOinstallations. The company also proposed that ship-owners upgraded ships in operation in order to meet the requirements of the EO-class, and this was soon an important activity. NSFI formed a special group for giving service to the shipping companies in connection with EO-installation. This group also developed a bridge control system of their own.

Ships being classified for EO-operation would normally be operated at night with unattended engine room, having an alarm system to call a duty engineer from sleep if a situation should arise that could not be tackled by the EO-system. During the daytime, the engineers would normally be occuped by maintenance work.

When the idea of ship automation was originally introduced, a main objective was crew reduction. As a matter of fact, EO-operation did not result in any reduction of engineers but it resulted in a better maintenance of machinery. The benefit for the shipping companies was lower repair cost and reduced off-hire time. This represented the principal advantage of ship automation.

\section{Introducing computer-based ship automation}

At the beginning of the nineteen sixties, computer-based systems for process control were introduced in industry and soon the idea of using the same technique for ship automation was presented. SINTEF actively promoted this idea. An early report was published, indicating several applications onboard where the use of computers would be favourable. At the same time, students at the University of Trondheim, NTH, were educated in this field and several of them used this subject for their diploma work. SINTEF, together with Norcontrol, made an early attempt to get a project started, but it was not possible to convince industrial partners to finance such an experiment.

Again we had to call upon NTNF and Servoteknisk Utvalg, and in 1967 an agreement was made, aiming at an installation of a computer-based system onboard, and being entirely financed by grants from NTNF. A project group was formed of participants from SINTEF, NSFI, DnV, the shipping company Wilh. Wilhelmsen and Norcontrol, and the management of the project was the responsibility of Norcontrol. This was the starting point for a very active period of development, introducing a next generation of ship automation facilities.

\section{Start of the Taimyr-project}

The shipping company Wilh. Wilhelmsen agreed to have an experimental computer-based system installed onboard their latest $\mathrm{M} / \mathrm{S}$ 'Taimyr', a dry cargo 
ship being built at Mitsui shipyard in Japan. It was decided that installation should take place after the ship was delivered from the yard.

The project work was started in March 1967. Basically, the computer system should be applied for several functions on board, functions which the project group evaluated to be applications where this technology could prove to be of value. After a period of evaluation it was decided to choose applications for navigational purposes, for engine room automation, for dry cargo handling and for wage calculations.

\section{The Taimyr-project}

The choice of computer was an important decision to be made. After having evaluated several computers, it was decided to purchase a NORD-1 computer from a Norwegian company, Norsk Data, founded in 1967. As a matter of fact the Project signed the first order that the company received, and that was in January 1968. A risky decision, but it proved to be a good one. Participants from SINTEF in the project group took the responsibility of developing an operating system.

The final system integration and testing were performed in Trondheim, the project group being brought here for this purpose. The system was installed on board 'Taimyr' in June 1969, and the ship left Europe for the Far East with 5 participants from the project group on board in order to put the system into operation. When the ship returned to Europe in September 1969, the system performed satisfactorily and it could already be concluded that the experiment was successful. The following sections will explain why.

\section{The computer-based navigation}

At an early stage it was decided to use the computer system for handling radar information in order to develop a system for cclision avoidance. For this purpose, the computer was connected to the radar for on-line data processing in order to disclose some of the information included in the radar picture. The system included automatic tracking of eight targets, initially pointed out by the operator by means of a marker. Heading and speed of targets were calculated, and the results displayed in the intersweep periods on a separate PPI as a vector line for each vessel, superimposed on the normal radar picture. An alarm was given when calculations of heading and speed indicated danger for collision. The operator could also simulate the predicted traffic situation based upon a manoeuvre proposal to avoid collision.

The presentation using vector lines for heading and speed gave the operator a very clear picture of the traffic situation to help him to take the right decisions. The system proved to be very reliable, and it was claimed that this was a first breakthrough since the introduction of radar. The captain of 'Taimyr' assured us that he could navigate more safely with this system in fog, than he could without it in bright weather!

\section{Computer-based engine room applications}

Primarily it was decided that the installation should have a complete alarm and safety system, as well as other functions to comply with the EO-requirements for periodically unattended engine room. The system exceeded the minimum require- 
ments to some extent. In an alarm situation the computer performed a scan through the system in order to indicate the primary alarm source. Reliability of sensors was investigated to some extent, and parameters were stored in order to detect trends in the measured values.

In addition to the alarm and safety system, the computer was controlling start/ stop of the auxiliary engines and connection of generators. Under normal conditions, one or two generators were running. In case of high measured or calculated load, or in case of malfunction of running units, the computer system would perform start, synchronising and switching-on of a stand-by generator unit. The primary purpose of this system was to ensure a continuous and sufficient power supply during both normal and abnormal conditions.

The system was also designed for condition control of main engine and of the hull in order to detect possible trends in the general condition. For the main engine, this control was applied to the fuel oil system, the scavenge air system, the exhaust gas system and the cylinders. Manual input was used for some parameters, but the majority was measured automatically and transferred to the computer on-line. Processed data were compared to normal-value functions, for example, scavenge air as a function of engine output. Normal values stored in the computer were based upon measurements during the first period of normal operation. Output to the operator consisted of calculated variations as percentages of normal value. Pressure variations in the cylinders were measured on-line by a portable unit.

Operation of the computer-based systems for engine room applications on board 'Taimyr' was also a successful part of the project. For the first time in history an engine room was operated unattended, being supervised by a computer! Experiences with the alarm and safety system indicated less false alarms than was the case with the conventional alarm system being installed at the yard.

\section{Cargo handling, wages and communication}

For the cargo handling a program was developed for load distribution, containing general data concerning loading/unloading facilities in all ports that would be called at by the ship, as well as data about the ship. The officer in charge of cargo handling would give as input to the program all necessary information about cargo to be handled. The computer then calculated estimated loading/unloading times for each of the hatches, as well as data concerning displacement, trim and stability of the ship. This program proved to be working satisfactorily, but there were difficulties in obtaining necessary information in advance about the cargo, preventing practical use of this program.

For the calculation of wages, another interactive program was developed. Detailed descriptions of all tariff ratings in force as well as the necessary information about the crew was stored in the computer. Data that might vary from one month to another was then specified by the operator. The computer would then make the calculations, ending up with payrolls and cheques being automatically printed out on the teleprinter. This program was tested with good results, but it was not used as a routine on board ' $T$ aimyr'.

For communication with the 'home' office, the computer was connected to the onboard telex, thus being able to transfer data concerning the running and the condition of the vessel as well as accounts for cargo and disbursement.

Having described all the successes, it should be added that there was also one 
major failure. That was a magnetic tape station, which should have been used for storing programs and data. It was never possible to make this station work satisfactorily, and that is why cargo handling and payroll calculations were not pursued more actively. These applications were, however, not sufficiently interesting to justify a replacement of storage facilities.

\section{Exploitation of the results from the Taimyr-project}

As NTNF had financed the project, both hardware and software were the property of this institution. As the end of the project period, in 1970, it was agreed that the company Wilh. Wilhelmsen should take over the installation onboard 'Taimyr' for a certain sum, but part of the agreement was that further experiences obtained should be reported and that the computer system could be used for other experiments in connection with NTNF activities.

Furthermore, an agreement was made with Norcontrol who were given the rights to use the results from the project for further development and marketing, paying royalty to NTNF for each subsequent installation. This agreement resulted in the development of DataBridge for navigational purposes and in DataChief for applications in the engine room, and these product lines have performed well. Some 300 installations have been delivered, and royalties were paid until the end of 1973 .

\section{Further research programme}

NTNF decided that the Taimyr-project should be followed by research serving the interests of Norwegian shipping. A committee was formed for this purpose, and at the end of 1970 the SDS-activity was launched. SDS, which stands for 'System for operation of ships', comprized several projects and only one third of them were to be of a technical nature. The rest of the research was devoted to economic and social problems.

One very important project related to ship automation was the Waage-project, being a joint effort of Norcontrol, Akergroup and NSFI. The purpose was to introduce computer-based instrumentation and control for the automation of a turbine tanker. An experimental installation was designed for the T/T 'Songa' of 285,000 dwt belonging to the shipping company Hagb. Waage and being built at Stord shipyard. In 1974 the ship left the yard with the experimental installation onboard, and the subsequent testing showed successful operation. More details will be given in the next section.

Another project which was part of the SDS-activity was related to hull stresses and the possibility of using instrumentation in order to obtain safer navigation in rough weather. Several investigations were made, including an experimental installation on board 'Taimyr', using the computer system of this ship for development work. A system was designed, using strain gauges and an accelerometer as sensing elements. Two companies obtained the rights to further develop and market this kind of system, either as part of a computer-based DataBridge or as a separate unit.

After the termination of the SDS-activity, further research and development related to hull surveillance were the subject of a project, sponsored by NTNF, DnV, Norcontrol and The Norwegian Maritime Directorate, as well as by some shipping companies. The aim of this SDS-project was to improve safety for crew, ship, cargo 
and environment, when sailing in rough weather. A comprehensive study was made, resulting in a better understanding of ship behaviour and stresses in rough waters. This knowledge was used to develop equipment and to educate navigators.

\section{The Waage-project}

In $\S 12$, general information about the project was given but the importance of this activity justifies more details.

The installation onboard T/T 'Songa' consists mainly of four systems for different functions. They are:

DataSafe which is an alarm and safety system, satisfying the requirements for EO-operations. This system will give more detailed information than a conventional alarm system, and it has an extensive automatic checking program for eliminating false alarms, as well as facilities for filtering and linearization of measurements.

DataSteam, which is boiler control, including the control of combustion, feed water and steam temparture, as well as management of burners. An advanced control system was developed, having a multi-variable coordination of the controller loops, using a multi-variable estimator, including Kalman filtering.

DataTurbine for remote control of turbines, providing an advanced strategy of control which contributed to improved economy.

DataTrend for condition monitoring and maintenance prediction, using a complete set of mathematical models for these purposes.

There is no doubt that this project represented an important step forward in the field of ship automation. Again, Norcontrol got the rights for further marketing and, in 1975 , this industrial activity had developed a complete family of computer-based systems for ship automation, comprising systems for navigation, diesel and turbine machinery, as well as for cargo handling in connection with tankers. These achievements were to a great extent based upon results from Norwegian research activities. But then came the shipping crisis, which reduced the possibilities for benefit and slowed down further activities in the field of ship automation.

\section{Ship automation results for other applications}

The expertise being obtained during several years of development in the field of ship automation, and especially the know-how regarding computer-based systems, could certainly be used for other applications which were less influenced by shipping economy.

One of these applications was simulators for training navigators and ship's engineers at the maritime schools. Development work in this direction was started in 1972 , and the first radar/navigation simulator was delivered in 1973 to a Norwegian maritime school, being followed by deliveries to nautical colleges in some 10 other countries. Simulators for engine room applications came somewhat later and the first delivery was in 1975.

Another similar field is traftic control in harbours and restricted waters, using the tracking technique, originally designed for the Taimyr collision avoidance system. By using this technique it is possible, in a central control room, to get a 
clear picture of the traffic situation in order to give the best advice. As safety considerations are becoming more and more important, there will be a growing market for these installations and, in recent years, a few systems of this kind have been installed abroad by Norwegian industry.

A third field is offshore applications, where computer-based on-line systems are being slowly introduced. The expertise in precise navigation has been applied for pipe laying and inspection, and the experiences from engine room automation have to some extent been applied for operation of drilling and production platforms. A recent field of activity is training simulators being used for the training of operators on drilling and production platforms. Safety and economic considerations are the arguments for this kind of training facilities.

\section{Concluding remarks}

The story of Norwegian research and development in the field of ship automation is an exciting story, most of the road being paved with success. It shows that even a small country, when concentrating important resources in a limited field and having a high level of education, may contribute to the application of new technology worldwide. A condition for success, however, is that the fields chosen for main efforts are fields of national importance and of international recognition. Another condition is that a cooperation can be established between research institutes, users and producers. In the case of Norwegian ship automation these conditions were satisfied, the results being applied to the benefit of shipping and industry.

It is hoped that the story will inspire others to explore new fields in a similar way. Several fields in connection with the offshore activity may offer these opportunities.

Finally, the author points to how fast technology is moving in the field of automation. In 1982, the 'Taimyr' computer-based installation was considered of historical interest and, 13 years after it was put into operation onboard, it was placed in The Shipping Museum at Bygdøy! 